University of Wollongong

Research Online

Faculty of Health and Behavioural Sciences -

Papers (Archive)

Faculty of Science, Medicine and Health

$1-1-2007$

\title{
EEG electrode caps can reduce SAR induced in the head by GSM900 mobile phones
}

Denise L. Hamblin

Vitas Anderson

Swinburne University of Technology

Robert L. McIntosh

Ray J. McKenzie

Swinburne University of Technology, Ray.McKenzie@team.telstra.com

Andrew W. Wood

Swinburne University of Technology

See next page for additional authors

Follow this and additional works at: https://ro.uow.edu.au/hbspapers

Part of the Arts and Humanities Commons, Life Sciences Commons, Medicine and Health Sciences Commons, and the Social and Behavioral Sciences Commons

\section{Recommended Citation}

Hamblin, Denise L.; Anderson, Vitas; McIntosh, Robert L.; McKenzie, Ray J.; Wood, Andrew W.; Iskra, Steve; and Croft, Rodney J.: EEG electrode caps can reduce SAR induced in the head by GSM900 mobile phones 2007, 914-920.

https://ro.uow.edu.au/hbspapers/148

Research Online is the open access institutional repository for the University of Wollongong. For further information contact the UOW Library: research-pubs@uow.edu.au 


\title{
EEG electrode caps can reduce SAR induced in the head by GSM900 mobile phones
}

\begin{abstract}
This paper investigates the influence of EEG electrode caps on specific absorption rate (SAR) in the head from a GSM900 mobile phone (217- $\mathrm{Hz}$ modulation, peak power output $2 \mathrm{~W})$. SAR measurements were recorded in an anthropomorphic phantom using a precision robotic system. Peak $10 \mathrm{~g}$ average SAR in the whole head and in just the temporal region was compared for three phantom arrangements; no cap, 64-electrode "Electro-Cap," and 64-electrode "Quick-Cap". Relative to the "no cap" arrangement, the Electro-Cap and Quick-Cap caused a peak SAR (10 g) reduction of $14 \%$ and $18 \%$ respectively in both the whole head and in the temporal region. Additional computational modeling confirmed that SAR $(10 \mathrm{~g})$ is reduced by the presence of electrode leads and that the extent of the effect varies according to the orientation of the leads with respect to the radiofrequency (RF) source. The modeling also indicated that the nonconductive shell between the electrodes and simulated head material does not significantly alter the electrode lead shielding effect. The observed SAR reductions are not likely to be sufficiently large to have accounted for null EEG findings in the past but should nonetheless be noted in studies aiming to measure and report human brain activity under similar exposure conditions.
\end{abstract}

\section{Keywords}

eeg, gsm900, head, sar, phones, mobile, can, caps, induced, reduce, electrode

\section{Disciplines}

Arts and Humanities | Life Sciences | Medicine and Health Sciences | Social and Behavioral Sciences

\section{Publication Details}

Hamblin, D. L., Anderson, V., McIntosh, R. L., McKenzie, R. J., Wood, A. W., Iskra, S. \& Croft, R. J. (2007). EEG electrode caps can reduce SAR induced in the head by GSM900 mobile phones. IEEE Transactions on Biomedical Engineering, 54 (5), 914-920.

\section{Authors}

Denise L. Hamblin, Vitas Anderson, Robert L. Mclntosh, Ray J. McKenzie, Andrew W. Wood, Steve Iskra, and Rodney J. Croft 


\title{
EEG Electrode Caps Can Reduce SAR Induced in the Head by GSM900 Mobile Phones
}

\author{
Denise L. Hamblin, Vitas Anderson, Robert L. McIntosh, Ray J. McKenzie, Andrew W. Wood, Steve Iskra, and \\ Rodney J. Croft*
}

\begin{abstract}
This paper investigates the influence of EEG electrode caps on specific absorption rate (SAR) in the head from a GSM900 mobile phone $(217-\mathrm{Hz}$ modulation, peak power output $2 \mathrm{~W})$. SAR measurements were recorded in an anthropomorphic phantom using a precision robotic system. Peak $10 \mathrm{~g}$ average SAR in the whole head and in just the temporal region was compared for three phantom arrangements; no cap, 64-electrode "Electro-Cap," and 64-electrode "Quick-Cap". Relative to the "no cap" arrangement, the Electro-Cap and Quick-Cap caused a peak SAR $(10 \mathrm{~g})$ reduction of $14 \%$ and $18 \%$ respectively in both the whole head and in the temporal region. Additional computational modeling confirmed that SAR (10 g) is reduced by the presence of electrode leads and that the extent of the effect varies according to the orientation of the leads with respect to the radiofrequency (RF) source. The modeling also indicated that the nonconductive shell between the electrodes and simulated head material does not significantly alter the electrode lead shielding effect. The observed SAR reductions are not likely to be sufficiently large to have accounted for null EEG findings in the past but should nonetheless be noted in studies aiming to measure and report human brain activity under similar exposure conditions.
\end{abstract}

Index Terms-EEG electrode leads, mobile phones, SAR.

\section{INTRODUCTION}

$\mathbf{M}$ EASUREMENTS of brain activity are commonly achieved using an arrangement of electrodes positioned on the scalp conveniently arranged in an electroencephalography (EEG) cap. For acute studies of mobile phone effects a number of issues arise from such arrangements including: 1) the possible corruption of recordings due to pick-up of mobile phone emissions by electrode leads; 2) the effect on specific absorption rate (SAR) in the head due to these leads being positioned between the scalp and active source of exposure.

Manuscript received September 23, 2005; revised September 3, 2006. Asterisk indicates corresponding author.

D. L. Hamblin is with the Brain Sciences Institute, Swinburne University of Technology, 400 Burwood Rd., Hawthorn, VIC 3122, Australia. She is also with the Australian Centre for Radiofrequency Bioeffects Research, Hawthorn, VIC 3122, Australia (e-mail: Denise.Hamblin@ sensometrics.com).

V. Anderson is with the Australian Centre for Radiofrequency Bioeffects Research, Hawthorn, VIC 3122, Australia. He is also with Kordia Australia Pty Ltd, Level 4, 170 Pacific Highway, St. Leonards, 2065 NSW, Australia.

R. L. McIntosh, R. J. McKenzie, and S. Iskra are with the Australian Centre for Radiofrequency Bioeffects Research, Hawthorn, VIC 3122, Australia.

A. W. Wood is with the Australian Centre for Radiofrequency Bioeffects Research, Hawthorn, VIC 3122, Australia. He is also with the Bioelectromagnetics Laboratory, Swinburne University of Technology, Hawthorn, VIC 3122, Australia.

*R. J. Croft is with the Brain Sciences Institute, Swinburne University of Technology, VIC 3122, Australia. He is also with the Australian Centre for Radiofrequency Bioeffects Research, Hawthorn, VIC 3122, Australia (e-mail: rcroft@swin.edu.au).

Digital Object Identifier 10.1109/TBME.2007.893486
Although these issues appear fundamental to defining the amount and type of exposure administered in various set-ups and determining the cause of subsequent findings, they are rarely accounted for or reported. We have recently addressed the issue of pick-up by electrode leads [1], and now address the issue of possible changes in SAR at the head by the arrangement of electrodes positioned on the scalp. A recent report by Angelone et al., based on computational modeling, suggested SAR enhancement of over five times due to electrodes on the scalp during MRI exposures to $128-\mathrm{MHz}$ radiofrequency (RF) [2]. However, the source characteristics, field distribution and frequency of RF exposure during MRI is substantially different to that experienced from a mobile handset placed against the head. In the latter case, the phone exposure is much more localised and the coupling response of the leads at the higher frequency of $900 \mathrm{MHz}$ may be substantially different.

Electroencephalography, a noninvasive measure of voltage fluctuations of large ensembles of neurons in the brain, has become a common method of investigation into the acute effects of mobile phone exposures on brain activity. There are a number of electrode positioning systems available for the measurement of human EEG. The traditional montage comprises 19 electrodes positioned in predetermined scalp locations according to the "International 10/20 System." However, as greater spatial information can be gained from additional electrodes, elasticized caps with 32,64 , or up to 256 channels have become widely available. The commonly used "Electro-Cap" (Electro-Cap International Inc., Eaton, $\mathrm{OH}$ ) has recessed electrodes with plastic supports and electrode wires running underneath the cap. A more recent design is the "Quick-Cap" (Neuroscan Inc., El Paso, TX), which has thicker and more elastic fabric, softer rubber supports surrounding the electrodes and bundled wiring running external to the cap.

The GSM900-type handset, operating in the frequency band of $890-915 \mathrm{MHz}$, has been the most commonly used mobile phone to study the effects of electromagnetic field (EMF) emissions on biological systems. For the purposes of testing human physiological responses to such emissions, handsets can be set via computer and manufacturer software to continuously transmit a GSM signal at a number of power levels, including the nominal maximum mean power output of $250 \mathrm{~mW}$ (peak power of $2 \mathrm{~W}$ ).

\section{SAR MEASUREMENTS}

\section{A. Materials and Methods}

SAR measurements were conducted inside an IEC 62209-1 [3] compliant Standard Anthropomorphic Model (SAM) 
TABLE I

DiELECTRIC PROPERTIES USED IN THE NUMERICAL MODELS

\begin{tabular}{ccc}
\hline Matter & $\sigma$ & $\varepsilon_{\mathrm{r}}$ \\
$(\mathrm{s} / \mathrm{m})$ & 0.97 & 41.5 \\
\hline Head $^{\mathrm{a}}$ & 0.0 & 4.8 \\
Phantom Shell $^{\mathrm{b}}$ & 11.2 & 60.3 \\
Electrode gel $^{\mathrm{c}}$ &
\end{tabular}

Source: ${ }^{\mathrm{a}}[5],{ }^{\mathrm{b}}$ Data provided by Aprel Inc. for the Specific Anthropomorphic Mannequin (SAM) phantom, ${ }^{\mathrm{C}}$ Dielectric properties measured

phantom. Although the phantom shell is nonconductive, there is nonetheless a displacement current across the shell similar to that associated with compact bone. According to Gabriel's figures [4], compact bone has a permittivity $\left(\varepsilon_{\mathrm{r}}\right)$ of 12.5 (c.f. 4.8 for phantom shell) and a conductivity $(\sigma)$ of 0.143 (c.f. 0 for phantom shell) at the frequency of interest $(900 \mathrm{MHz})$, resulting in a 2.6-fold difference in magnitude of displacement current. As SAR is being measured in what would normally be the brain, the current cap/no-cap comparisons were considered as representative of a real measurement scenario.

The SAR measurements were made using a precision robot RF Dosimetric Assessment System (DASY4, Schmid \& Partner Engineering AG). The total electric field strength, E, was measured with the built-in miniature isotropic E-field probe (Model ET3DV6, 5-mm resolution, $2.5^{3} \mathrm{~mm}^{3}$ volume). The specific energy absorption rate, SAR in W/kg, was calculated as SAR = $\sigma|\mathrm{E}|^{2} / \rho$, where $\sigma$ is the electrical conductivity of the medium $(\mathrm{S} / \mathrm{m}), \mathrm{E}$ is the in situ electric field strength $(\mathrm{V} / \mathrm{m} \mathrm{rms})$ and $\rho$ is the mass density $\left(\mathrm{kg} / \mathrm{m}^{3}\right)$ of the medium. All measurements were conducted at EMC Technologies (Australia), accredited by the Australian National Association of Testing Authorities (NATA) for conducting SAR compliance measurements. The phantom was filled with a dielectric tissue fluid (Table I) compatible with frequencies of around $900 \mathrm{MHz}(\sigma=0.97 \mathrm{~S} / \mathrm{m}$; $\varepsilon_{\mathrm{r}}=41.5 ; \rho=1000 \mathrm{~kg} / \mathrm{m}^{3}$; sourced from an Australian SAR compliance measurement standard [5] and representing an average head material according to [3]. A Nokia 6110 mobile phone (estimated peak SAR of $0.870 \mathrm{~W} / \mathrm{kg}$; (Sarvalues.com Inc., 2001) was held in the "touch" position (specified by FCC Guidelines [6]), routinely used in compliance testing and comparable to normal use (see Fig. 1). The variability of distance and angle between the phone and the phantom were kept constant by the use of a plastic vice-like holder that could be accurately lowered or raised while retaining all other positional characteristics. Measurements were taken from the left side of the phantom head only.

A 64-electrode Electro-Cap and a 64-electrode Quick-Cap were employed in the current study. For both arrangements, the left side of the cap was stretched over the phantom and taped into position with electrodes FPZ (midline pre-frontal) and OZ (midline posterior) placed relative to the nasion and inion respectively. This was done so with reference to the International 10-20 System. The side of each cap, where a chin-strap would usually attach, was taped below the ear towards the chin and the opening for the ear (featured on the Quick-Cap only) was positioned over the earlobe. The electrodes were placed directly in

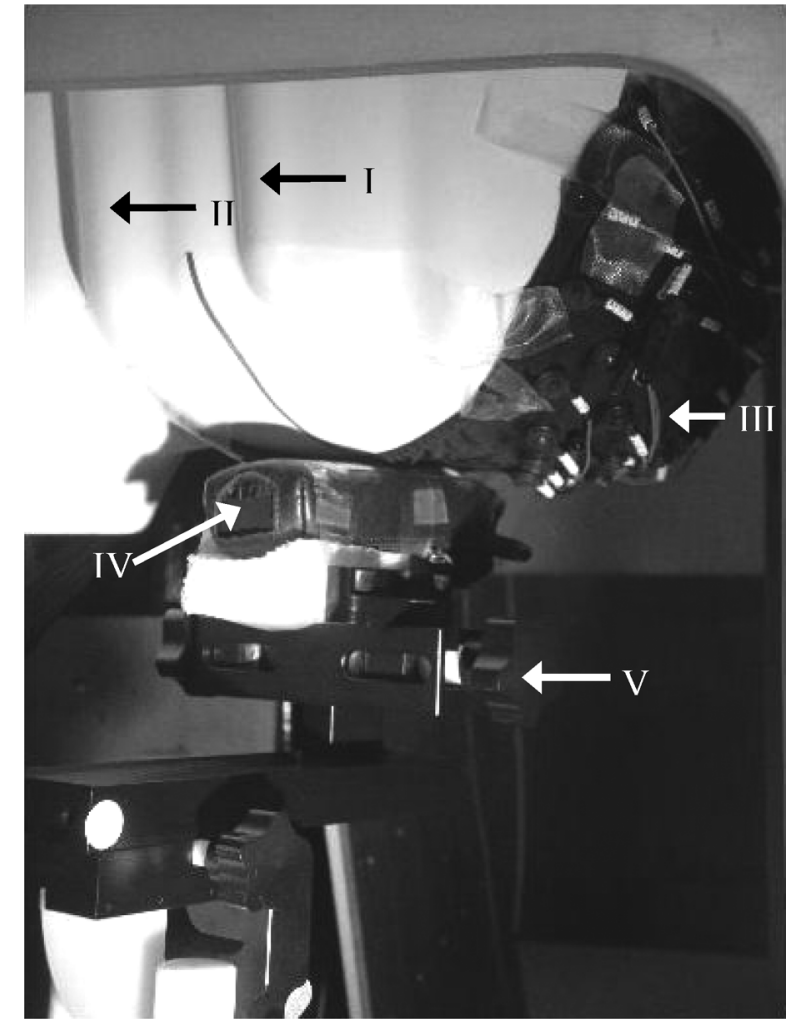

Fig. 1. Mobile phone held in "touch" position to phantom head by vice in the Quick-Cap arrangement. I. Phantom "nose"; II. Phantom "chin"; III. Electrode lead; IV. Test phone; V. Vice.

contact with the fiberglass shell. To replicate real testing conditions, conductive gel was injected through perforations in the electrodes via a blunt needle and electrode leads hanging from the caps were taped along the back of the phantom head, neck and torso.

Each test took 30 min, during which time the mobile phone was set to transmit a GSM digital signal (in this case at 895 $\mathrm{MHz}$ ) at the maximum output power. Prior testing of the battery showed that it retained $>90 \%$ charge for the first 2.5 hours, after which it rapidly dropped to $50 \%$. Between tests the mobile phone was turned off and attached to a charger for approximately $30 \mathrm{~min}$.

During measurement of the whole head SAR, DASY software was set to conduct an area scan $(131 \times 61 \times 1$ points, $15-\mathrm{mm}$ resolution) inside the phantom opposite the phone. From this area, the probe detected the exact location of peak SAR in the head which typically occurs on the near side to the phone between the temple and the cheek. This determined where the $(30-\mathrm{mm})^{3}$ average SAR measurement grid $(7 \times 7 \times 7$ points $)$ and $10 \mathrm{~g}$ cube with the highest averaged SAR values would be positioned (see Figs. 2 and 3). Three phantom arrangements were tested: 1) no cap, 2) 64-electrode Electro-Cap, and 3) 64-electrode Quick-Cap. For both caps, electrodes were 6-mm-diameter tin alloy disks, and leads were metallic foil wrapped around a Teflon fiber former, with a nonconductive sheath. To determine SAR in the brain, DASY software was instead set to measure the average SAR values from a $(30-\mathrm{mm})^{3}$ measurement grid placed in-line with the phone's antenna (see Fig. 3), higher in the head and over the "temporal lobe" which is expected to be the region 


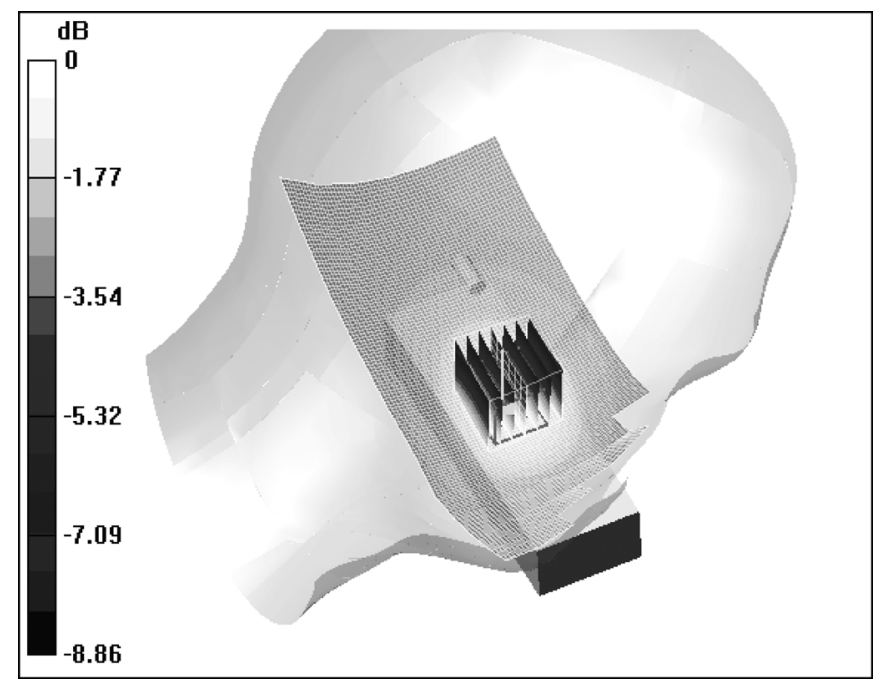

Fig. 2. Measurement plot for maximum Head SAR during "no cap" condition. The probe conducted an area scan $(131 \times 61 \times 1$ points, 15 -mm resolution $)$ from which it determined the position of the $(30-\mathrm{mm})^{3}$ average SAR measurement grid $(7 \times 7 \times 7$ points, 5 -mm resolution) and $10 \mathrm{~g}$ cube with the highest averaged SAR values in the phantom head.

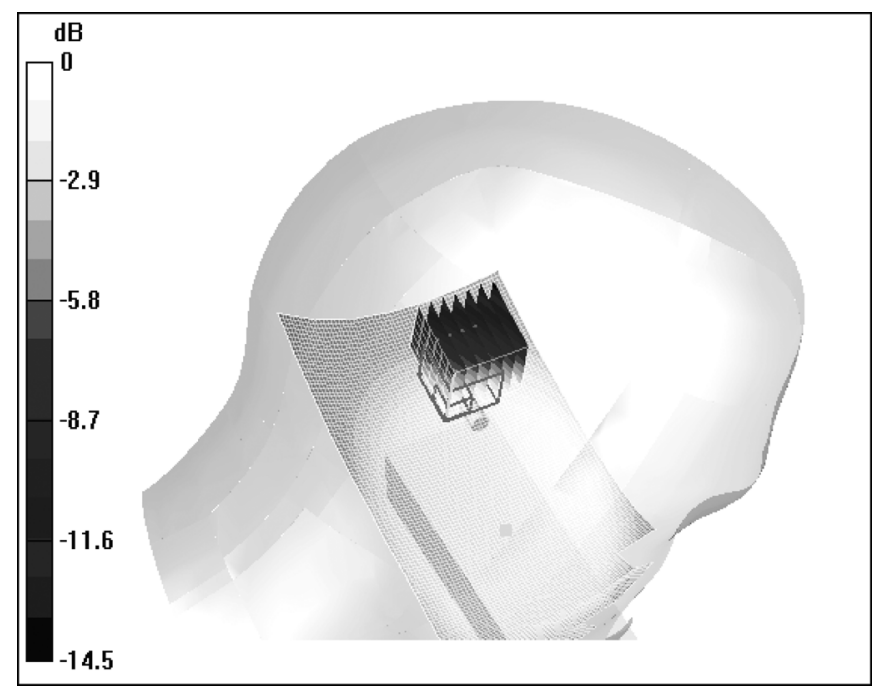

Fig. 3. Measurement plot for maximum Brain SAR during "no cap" condition. The probe conducted an area scan from which it determined the position of the $(30-\mathrm{mm})^{3}$ average SAR measurement grid and $10 \mathrm{~g}$ cube with the highest averaged SAR values in-line with the antenna.

of highest brain SAR and hence the most indicative of any putative RF neurological effect. The same three phantom arrangements were tested. Ambient and tissue fluid temperatures were constant over the duration of each test $\left(22.0^{\circ} \mathrm{C}\right.$ ambient, 21.8 ${ }^{\circ} \mathrm{C}$ liquid).

\section{B. Results}

As can be seen in both Table II and Fig. 4, there was a difference between each phantom arrangement investigated for both maximum SAR in the whole head (Head SAR) and maximum SAR in the chosen region of the brain (Brain SAR). Relative to the "no cap" arrangement, the SAR for both the Electro-Cap and Quick-Cap arrangements were reduced. This result was consistent in magnitude and direction at both measurement sites.
TABLE II

PEAK SAR VALUES AND CORRESPONDING REDUCTIONS FOR DIFFERENT PHANTOM ARRANGEMENTS

\begin{tabular}{ccccc}
\hline \multirow{2}{*}{ Arrangement } & \multicolumn{2}{c}{ Whole Head $^{\mathrm{a}}$} & \multicolumn{2}{c}{ Temporal Region Only $^{\mathrm{b}}$} \\
\cline { 2 - 5 } & Peak SAR* & \% Reduction & Peak SAR* & \% Reduction \\
\hline No Cap & $0.674(0.899)$ & -------- & $0.110(0.190)$ & -------- \\
Electro-Cap & $0.574(0.758)$ & $14.8(15.68)$ & $0.095(0.163)$ & $13.6(14.21)$ \\
Quick-Cap & $0.552(0.744)$ & $18.1(17.24)$ & $0.090(0.158)$ & $18.2(16.84)$
\end{tabular}

${ }^{a}$ Measured value taken from area where maximum SAR was found in the phantom head-typically on the near side of the face between temple and cheek

${ }^{\mathrm{b}}$ Measured value taken from region over temporal lobe (in-line with antenna) *SAR in units of W/kg and averaged over $10 \mathrm{~g}$ of tissue ( $1 \mathrm{~g}$ average measurements shown in brackets)

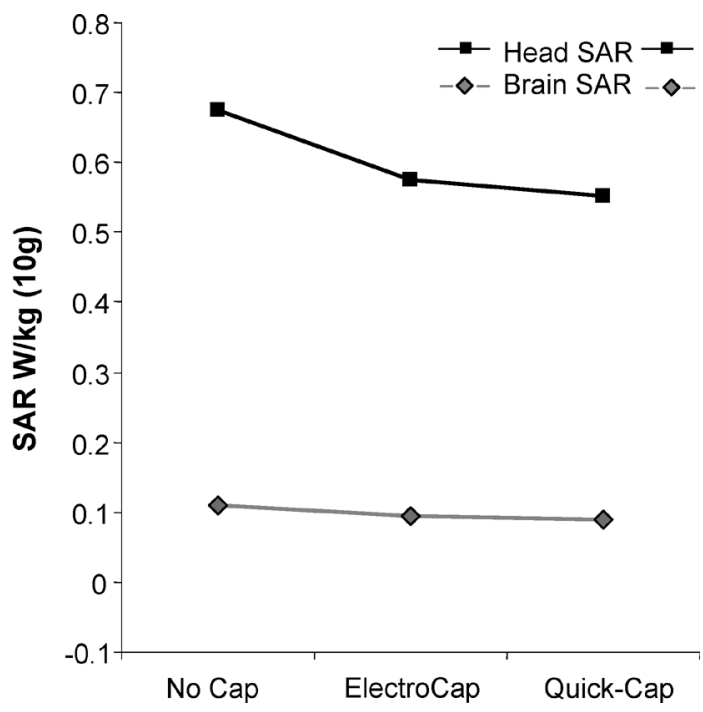

Fig. 4. Measured peak $10 \mathrm{~g}$ average SAR values in the three different phantom arrangements.

The difference between the power output of the phone at the start and end of each SAR measurement was reported as a power drift value. These values were determined by a reference measurement made by the probe immediately before and after each test and were minimal for all tests reported here (ranging from $-0.4 \mathrm{~dB}$ to $0.2 \mathrm{~dB})$.

Peak SAR $(10 \mathrm{~g})$ values in the head were $0.674 \mathrm{~W} / \mathrm{kg}$ for no cap, $0.574 \mathrm{~W} / \mathrm{kg}$ for Electro-Cap (14.8\% decrease), and 0.552 W/kg for Quick-Cap (18.1\% decrease). Peak SAR (10 g) values within the preset measurement grid, in-line with the phone's antenna and over the temporal lobe were $0.110 \mathrm{~W} / \mathrm{kg}$ for no cap, $0.095 \mathrm{~W} / \mathrm{kg}$ for Electro-Cap (13.6\% decrease), and $0.090 \mathrm{~W} / \mathrm{kg}$ for Quick-Cap (18.1\% decrease).

\section{Computational Modeling}

The measured reduction in SAR is consistent with an expectation that the leads provide a partial shield to the incident RF energy. However, in light of the results reported by Angelone et al. [2], computational modeling of our test set-up was employed to explore the issue more thoroughly. In particular, we were concerned to investigate the suggestion that the presence 
TABLE III

SAR, POWER, AND IMPEDANCE STATISTICS FOR VARIOUS MODEL SCENARIOS

\begin{tabular}{|c|c|c|c|c|c|c|c|c|c|}
\hline & Numeric & al model & escription & & $\begin{array}{r}\text { Calcul } \\
\text { ante }\end{array}$ & $\begin{array}{l}\text { ated dipole } \\
\text { nna data }\end{array}$ & (for & $\begin{array}{r}\mathrm{SAR}(\mathrm{W} / \mathrm{l} \\
\text { het power nor } \\
250 \mathrm{~mW}\end{array}$ & alized to \\
\hline $\begin{array}{l}\text { Model } \\
\#\end{array}$ & $\begin{array}{l}\text { Angle between } \\
\text { electrode leads } \\
\text { and dipole in yz } \\
\text { plane of Fig. } 5\end{array}$ & $\begin{array}{c}\text { Shell } \\
\text { present }\end{array}$ & $\begin{array}{c}\text { Electrodes } \\
\text { electrically } \\
\text { connected to } \\
\text { head }\end{array}$ & $\begin{array}{l}\text { See } \\
\text { Figure }\end{array}$ & $\begin{array}{l}\text { Net } \\
\text { power }^{\mathrm{a}} \\
(\mathrm{mW})\end{array}$ & $\begin{array}{l}\text { Impedance } \\
\text { (ohms) }\end{array}$ & $\begin{array}{l}\text { Whole } \\
\text { head } \\
\text { average }\end{array}$ & $\begin{array}{l}\text { Peak } 10 \mathrm{~g} \\
\text { average } \\
\text { (adjacent to } \\
\text { dipole feed- } \\
\text { point) }\end{array}$ & $\begin{array}{c}\text { 10g average } \\
\text { adjacent to } \\
\text { central } \\
\text { electrode }^{\mathrm{b}}\end{array}$ \\
\hline 1 & $0^{\circ}(/ /)$ & Yes & No & $5,6 \mathrm{~B}, 7 \mathrm{~A}$ & 163 & $19.6-\mathrm{j} 13.7$ & 0.046 & 1.14 & 0.607 \\
\hline 2 & $0^{\circ}(/ /)$ & Yes & Yes & $7 \mathrm{~B}$ & 160 & $19.0-\mathrm{j} 12.8$ & 0.043 & 1.23 & 0.595 \\
\hline 3 & $0^{\circ}(/ /)$ & No & Yes & $7 \mathrm{C}$ & 156 & $18.2-\mathrm{j} 14.5$ & 0.042 & 1.27 & 0.595 \\
\hline 4 & $15^{\circ}$ & Yes & No & & 212 & $32.4-\mathrm{j} 6.1$ & 0.048 & 1.21 & 0.529 \\
\hline 5 & $45^{\circ}$ & Yes & No & & 239 & $47.3-\mathrm{j} 1.3$ & 0.059 & 1.44 & 0.384 \\
\hline 6 & $90^{\circ}(\perp)$ & Yes & No & & 241 & $49.6+j 4.3$ & 0.054 & 1.84 & 0.076 \\
\hline 7 & No electrodes & Yes & No & $6 \mathrm{~A}$ & 241 & $49.5-\mathrm{j} 2.7$ & 0.054 & 1.85 & \\
\hline 8 & $\begin{array}{l}\text { Dipole in free } \\
\text { space }\end{array}$ & & & & 250 & $76.1+\mathrm{j} 2.4$ & & & \\
\hline
\end{tabular}

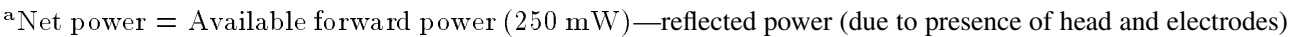

$\mathrm{b} 14 \mathrm{~mm}$ in from edge of skin, beneath electrode

\section{A}

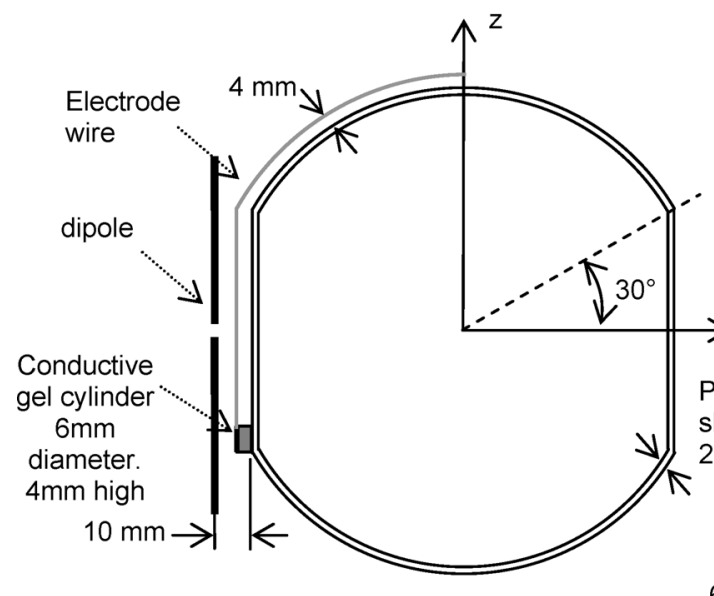

B

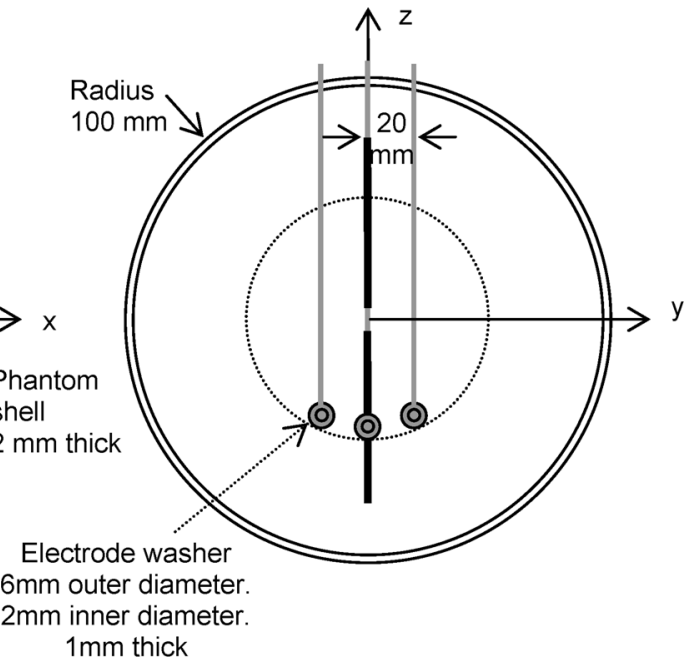

Fig. 5. An example of a computational model scenario considered (model \#1) with the 900-MHz dipole directly adjacent to an electrode and parallel to two other electrodes (A) front view (B) side view.

of the nonconductive phantom shell between the electrodes in the cap and the simulated head material would reduce any RF energy deposited due to direct conduction along the EEG leads compared to that in a real head where the insulating shell was not present.

\section{A. Materials and Methods}

To investigate RF pickup and conduction by the EEG leads, several computational models were constructed using commercial EM modeling software (Remcom XFDTD) based on the finite difference time domain (FDTD) technique to test various scenarios. The models (\#1-7 in Table III) comprised a simplified phantom head shape $(200-\mathrm{mm}$-diameter sphere with flat- tened surfaces on either side to represent the sides of the head) with a 2-mm-thick dielectric shell filled with homogenous tissue conforming to that used in our measurements (see Fig. 5 and Table I). The finite-difference cells were cubical with sides of length $1 \mathrm{~mm}$. A simplified arrangement of three parallel EEG leads was included in the models to simulate the worst case coupling condition between the RF source (modeled as a $900-\mathrm{MHz}$ dipole placed $10 \mathrm{~mm}$ from the side of the head) and the EEG leads, which occurs when the dipole is aligned parallel to the EEG leads nearest the dipole. The EEG electrodes and conducting gel used in the EEG caps were modeled based on their physical dimensions and measured dielectric properties. 


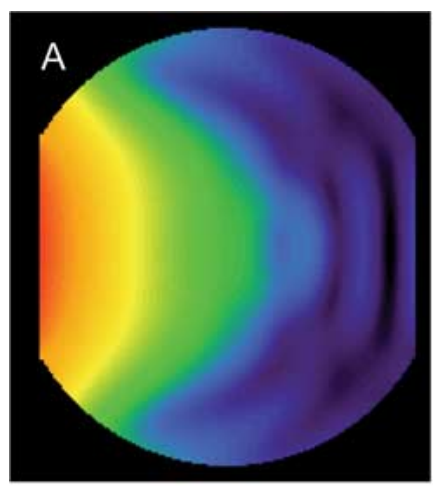

Scale: $\mathrm{dB}$ scale with $0 \mathrm{~dB}=10 \mathrm{~W} / \mathrm{kg}$

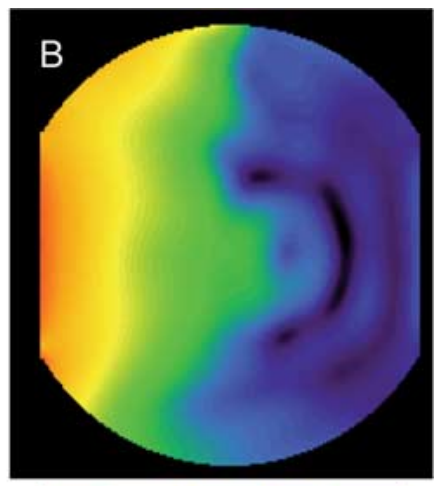

$-9 \quad-18$
Fig. 6. Comparison, for the $900-\mathrm{MHz}$ dipole, of the SAR in the head for: (A) No electrodes present (model \#7) (B) Electrodes present (as in Fig. 5 and model \#1). See SAR values and further data in Table III. Each plot is from a central slice in the head as shown in Fig. 5(a).

The dipole was $157 \mathrm{~mm}$ long $(0.47 \lambda)$ with a wire diameter of $1 \mathrm{~mm}$. It was designed with a generator voltage of $8.45-\mathrm{V}$ rms and antenna impedance of $73 \Omega$ so that it was well matched into free space producing a maximum available output power of $250 \mathrm{~mW}$ (model \#8). It is well known that antenna impedance may be significantly altered by capacitive coupling of the antenna with nearby objects (such as a head), thereby reducing its impedance match to the source and causing a reduced radiated power due to the power reflected back from the antenna feed. Our models enabled comparison of net input and reflected power due to the presence of the head and various configurations of the electrodes (Table III). In Table III the SAR values are presented when the net input antenna power is normalized to $250 \mathrm{~mW}$ in all models considered.

\section{B. Results}

In order to validate our measured data, we first compared the model with no electrodes around the head (model \#7) to the models containing three parallel electrodes oriented at $0^{\circ}, 15^{\circ}$, $45^{\circ}$ and $90^{\circ}$ to the dipole in the yz plane of Fig. 5 (models \#1, 4, 5,6 ). The peak $10 \mathrm{~g}$ averaged SAR was reduced by up to $38 \%$ when the leads were parallel to the dipole orientation (model $\# 1$ ), and was virtually unaffected when the leads were perpendicular (model \#6; Fig. 6). See Table III for details. Further, as expected, the $10 \mathrm{~g}$ SAR values near the electrodes decrease substantially as the distance from the dipole to the electrode increases (last column in Table III). This is also consistent with reduced induction of RF energy into the leads when perpendicular to the axis of the dipole. We would expect measured results to occur somewhere between these two extremes, depending on the exact arrangement of the EEG leads on the head, which is not precisely reproducible from experiment to experiment and represents one of the sources of uncertainty in this study.

Second, in order to determine if the phantom shell had an effect on the conduction path between the electrode and the phantom gel, a comparison was made between model \#1 and model \#2. In model \#1 the electrodes were attached to the shell as in the measurement situation, whereas in model \#2 the electrodes were attached directly to the simulated head tissue which more accurately represents EEG placement on real human subjects. The results of this modeling indicated that when the electrode was directly connected to the head, the peak $10 \mathrm{~g}$ averaged SAR is $8.1 \%$ higher, and the $10 \mathrm{~g}$ averaged SAR near the electrode closest to the source was lower by $2.0 \%$ [Fig. 7(a) and (b) and Table III]. These differences are small in the context of the uncertainty in the measurement system $( \pm 30 \%)$ and a comparable uncertainty in the FDTD calculation [7]. Fig. 7(c) also shows the minimal effect of the presence of the shell regardless of the leads (model \#3). Note also that in these three model scenarios with parallel electrodes (\#1-3), that the feed point impedance of the source does not vary significantly. This is also a good indicator that the energy absorbed in the head is not much different between those scenarios. Clearly then, any measurement result will be dominated by the much larger shielding effect of the EEG leads in this test setup.

\section{DISCUSSION AND CONCLUSION}

The current measurement results show that EEG electrode leads can produce a shielding effect, reducing the SAR in head regions close to the antenna and also where the maximum value is obtained. This is true for at least two electrode positioning systems commonly used in this area of research: the 64-electrode Electro-Cap and the 64-electrode Quick-Cap. This reduction in SAR was confirmed by subsequent computational modeling which suggested that the use of a nonconductive shell in this particular experimental setting did not significantly affect the results.

Although we were unable to measure possible electric field enhancement within the immediate vicinity of the electrodes (probe resolution $=5 \mathrm{~mm}$ ), our computational modeling does not indicate that this would be significant. Such enhancement is dependent on the particular arrangement of the lead wires and the power and properties of the exposure source in any given case, and cannot be modeled precisely. However, since the average power of the phone is $250 \mathrm{~mW}$ and there are many electrodes in the area over which this energy is absorbed, then in general we do not expect a noticeable amount of localized heating from the small enhancements predicted. In contrast, if the power level was greatly increased, as is possible in MRI, such as treated by Angelone et al. [2], then these small enhancements may result in measurable temperature changes near the electrodes, especially given that the SAR distribution in the head would also be much different. Overall, our investigation indicates that due to the different electrode arrangements and composition, EMF frequencies, exposure sources and experimental parameters utilized, these two studies are not comparable.

As peak and average SAR values were reduced, positive EEG findings in the area of mobile phone bioeffects may not be explained by electrode configurations acting like an antenna and greatly enhancing the SARs. As the measured reductions were less than $18.2 \%$ (worst case, Quick-Cap, brain SAR, $10 \mathrm{~g}$ ), the current results also fail to support the view that null findings are due to grossly attenuated SARs. The reductions observed were small compared to the error budget for such measurements (typically $\pm 30 \%$ ) and SAR variation expected due to differences in positioning of the phone [7]. For accurate dosimetry, it is 

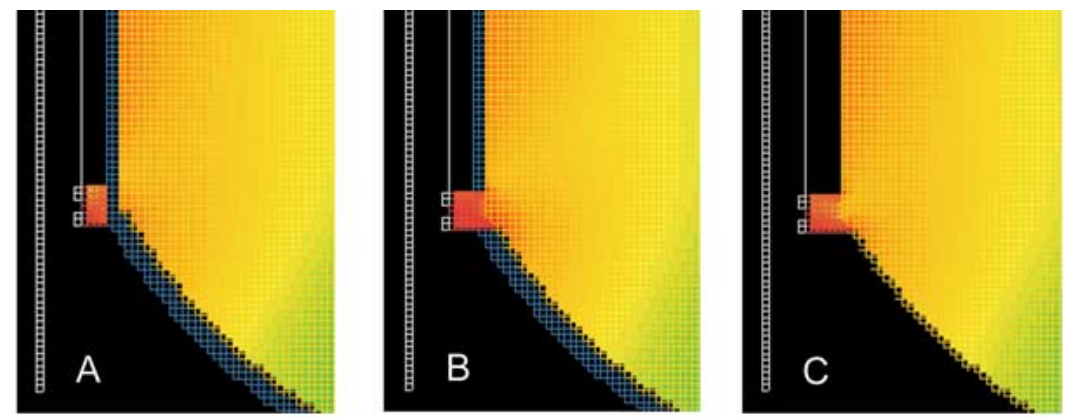

Scale: $\mathrm{dB}$ scale with $0 \mathrm{~dB}=10 \mathrm{~W} / \mathrm{kg}$

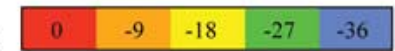

Fig. 7. Comparison, for the 900-MHz dipole, of the SAR in the head for (a) Electrode attached to shell (close-up from Fig. 5(B) with mesh present) (model \#1), b) Electrode attached to head (electrode gel extended through shell) (model \#2), c) Electrode attached to head and no shell present (model \#3). See the SAR values and further data in Table III.

nonetheless important that these reductions are accounted for and reported by those utilizing similar experimental conditions.

\section{ACKNOWLEDGMENT}

The authors would like to thank Telstra Research Laboratories and C. Zombolas of EMC Technologies for providing the equipment for this investigation. They would especially like to thank P. Jakubiec, also of EMC Technologies, for his assistance and valuable advice.

\section{REFERENCES}

[1] A. W. Wood, D. L. Hamblin, and R. J. Croft, "The use of a phantom scalp to assess the possible direct pickup of mobile phone handset emissions by electroencephalogram electrode leads," Med. Biol. Eng. Comput., vol. 41, pp. 470-472, Jul. 2003.

[2] L. M. Angelone, A. Potthast, F. Segonne, S. Iwaki, J. W. Belliveau, and G. Bonmassar, "Metallic electrodes and leads in simultaneous EEGMRI: Specific absorption rate (SAR) simulation studies," Bioelectromagnetics, vol. 25, pp. 285-295, May 2004.

[3] IEC 62209-1: Human Exposure to Radio Frequency Fields From HandHeld and Body-Mounted Wireless Communication Devices-Human Models, Instrumentation, and Procedures-Part 1: Procedure to Determine the Specific Absorption Rate (SAR) for Hand-Held Devices Used in Close Proximity to the Ear (Frequency Range of $300 \mathrm{MHz}$ to $3 \mathrm{GHz}$ ), , Int. Electrotech. Commission (IEC), Geneva, Switzerland, 2005.

[4] C. Gabriel, Compilation of the Dielectric Properties of Body Tissues at RF and Microwave Frequencies Brooks Air Force Tech. Rep. AL/OE-TR-1996-0037, 1996 [Online]. Available: http://www.fcc.gov/fcc-bin/dielec.sh, [Last accessed 1 Aug 2006]

[5] Radiocommunications (Electromagnetic Radiation-Human Exposure) Standard, Australian Communication Authority (ACA), Australia, 2003.

[6] Evaluating Compliance With FCC Guidelines for Human Exposure to Radiofrequency Electromagnetic Fields, , Federal Communications Commission (FCC) Office Eng. Technol., Washington, DC, 2001, OET Bull. 65, Supplement C.

[7] B. B. Beard and W. Kainz, "Review and standardization of cell phone exposure calculations using the SAM phantom and anatomically correct head models," Biomed. Eng. Online, vol. 3, p. 34, 2004.

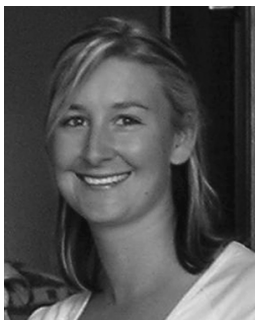

Denise L. Hamblin After successfully completing a Bachelors of Applied Science degree, she completed Honors degree in psychophysiology at Swinburne University of Technology, Hawthorn, Australia, in 2001. Her Honours degree research examined the effect of electromagnetic fields emitted by mobile phones on human brain activity. This research provided preliminary data for her Ph.D. degree project which focused specifically on the effect of mobile phone exposure on human event-related potentials, event-related synchronisation, reaction time, and psychological arousal, and additionally addressed a number of technical issues regarding potential EMF interference with various recording equipment.

Dr. Hamblin received first class Honors and her Ph.D. degree at Swinburne University.

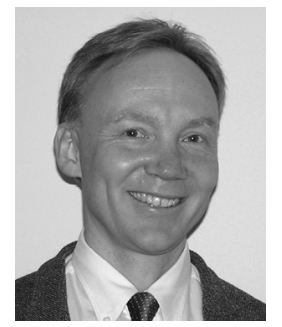

Vitas Anderson is an Engineer and Biophysicist with extensive experience in radiofrequency bioeffects research and safety assessment issues. Although he has been engaged in human and in vitro RF bioeffects studies, his main research interest lies in the area of $\mathrm{RF}$ and thermal dosimetry, particularly with regard to assessing safe human RF exposures.

Dr. Anderson actively participates in standards committees for RF safety and assessment, both nationally in Australia and internationally for the IEEE and IEC standards organizations. $\mathrm{He}$ is a member of the Australian Centre for RF Bioeffects Research and is with the by THL Australia as an RF Safety Consultant.

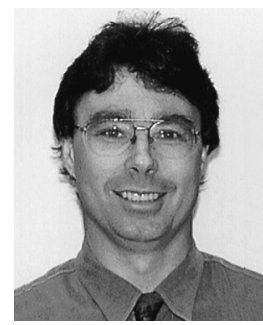

Robert L. McIntosh received the Ph.D. degree in mathematics from the Australian National University, Canberra, Australia, in 1989, in the area of PDEs.

He has been a member of the Electromagnetic Energy (EME) Safety Research team at Telstra Research since 1999, developing and applying a numerical modelling environment for the study of RF dosimetry, and human body absorption and thermal modelling. He is an Associate Investigator at the Australian Centre for Radio-Bioeffects Research (ACRBR). He has worked at the BHP Research Laboratories on the development of electromagnetic levitation, pumping, and braking devices for liquid metal, and new techniques in noise reduction in electromagnetic geophysics (1989-1999).

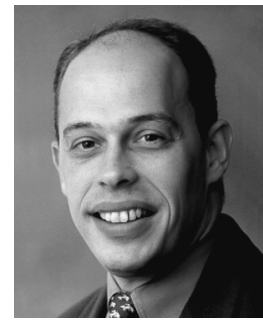

Ray J. McKenzie is a Scientist with the EME Research and Standards Group of the Telstra Chief Technology Office, investigating the effects of human exposure to electromagnetic energy (EME). $\mathrm{He}$ is also Research Director, Dosimetry, for the Australian Centre for Radiofrequency Bioeffects Research (ACRBR), and Senior Associate at RMIT University.

Dr. McKenzie is a member of the IEEE International Committee on Electromagnetic Safety (ICES), participates in IEC TC106/PT62232 (RF assessment) and is a technical assessor for the National Association of Testing Authorities (NATA). He is a member of the Applied Computational Electromagnetic Society (ACES) and the Bioelectromagnetics Society (BEMS). 


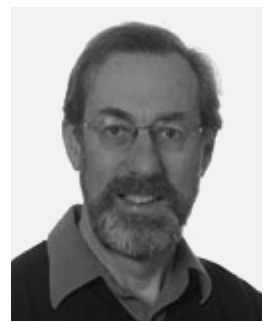

Andrew W. Wood received the B.Sc. degree in physics from Bristol University, Bristol, U.K., and the Ph.D. degree in biophysics from London University, London, U.K.

$\mathrm{He}$ is currently Professor at the Brain Science Institute at Swinburne University, Hawthorn, Australia, with a research interest in possible health effects of electromagnetic radiation. He is a Research Director with the Australian Centre for Radiofrequency Bioeffects Research.

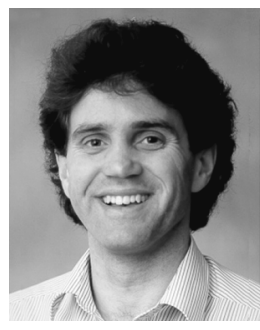

Steve Iskra received the B.E. (Hon.) degree in electrical engineering from the University of Melbourne, Melbourne, Australia, in 1982.

In 1982, he joined the Telstra Research Laboratories and has specialized in the areas of EMC and in the interaction of radio waves on the human body and on medical devices.

Dr. Iskra is a member of the International Special Committee on Radio Interference (CISPR) and Committee TE/3, Electromagnetic Interference, of Standards Australia.

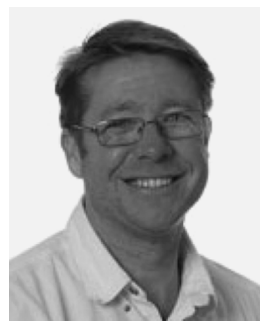

Rodney J. Croft obtained the Ph.D. degree in psychology from University of Wollongong, Wollongong, Australia, designing algorithms for accounting for ocular artefact in the electroencephalograph.

$\mathrm{He}$ is the Executive Director of the Australian Centre for RF Bioeffects Research (ACRBR), a government-funded consortium whose objective is to understand possible health implications of RF energy. Within this he is also a Research Director, heading the human neurophysiology research. He is Professor of Cognitive Neuroscience at the Brain Sciences Institute, Swinburne University, Hawthorn, Australia, where he also conducts research on issues concerned with electroencephalography methodology, and the neurobiology of clinical populations. 